\title{
Anterior Cruciate Ligament Injury in Association With Other Knee Injuries in King Abdulaziz University Hospital, Saudi Arabia
}

Ahmad M. Tayeb ${ }^{1}$, Abdullah A. Almohammadi ${ }^{1}$, Adel H. Hegaze ${ }^{1}$, Fawziah Roublah ${ }^{1}$, Khulood A. Althakafi $^{1}$

1. Orthopaedic Surgery, College of Medicine, King Abdulaziz University, Jeddah, SAU

Corresponding author: Ahmad M. Tayeb, ahmad.tayeb1997@gmail.com

\section{Abstract \\ Purpose}

The purpose of this study was to study the association of anterior cruciate ligament (ACL) injury with meniscal, collateral ligament, and bone injuries using magnetic resonance imaging (MRI) for clinical correlation during ACL repair.

\section{Methods}

This was a retrospective cohort study conducted on 136 patients diagnosed with ACL injury by MRI at King Abdulaziz University Hospital (KAUH) between September 2010 and September 2018.

\section{Results}

The medial meniscus was injured in approximately half (49.3\%) of patients, while the lateral meniscus was injured in $16.2 \%$. Regarding collateral ligament injuries, the medial collateral ligament was injured in six patients (4.4\%), the lateral collateral ligament in four patients (2.9\%), and both collateral ligaments in three patients (2.2\%). There was a significant relationship between the age group and the side of ACL injury $(\mathrm{P}<0.05)$ but not between the age group and the presence of an associated injury.

\section{Conclusion}

There was no significant relationship between ACL injury and menisci, collateral ligament, or bone injury.

Categories: Orthopedics

Keywords: anterior cruciate ligament (acl), meniscal tear, collateral ligament injury, bone injury

Received 08/18/2020

Review began 08/25/2020 Review ended 09/01/2020 Published 09/04/2020

๑) Copyright 2020

Tayeb et al. This is an open access article distributed under the terms of the Creative Commons Attribution License CC-BY 4.0., which permits unrestricted use, distribution, and reproduction in any medium, provided the original author and source are credited.

\section{Introduction}

Athletes are at high risk for injuries because they turn on an axis of rotation, turn while decelerating, and repeatedly jump and land. The knee is one of the most commonly injured sites [1]. The knee joint can be divided functionally into two separate joints: the tibiofemoral and the patellofemoral joints [2]. Its articular surfaces are represented by the femoral condyles, which are connected with the corresponding tibial plateau and in between them are the medial and lateral menisci [3]. The stability of the knee is mainly generated by the interaction of the capsule and its ligaments, menisci, muscles, and the cruciate ligaments [3].

The anterior cruciate ligament (ACL) plays an important role as a knee-stabilizing ligament that is frequently injured in athletes and trauma patients [4]. ACL is the major fixating ligament against anterior dislocation of the tibia. ACL is also a minor fixator to valgus rotation [5].

The ACL is one of the most recurrently injured knee ligaments, especially among young athletes [6]. Each year, more than 100,000 new cases of ACL injuries occur (most of these injuries occur as non-contact injuries), and approximately 75,000 ACL reconstructions are performed in the United States [7,8].

The study by Alrubayyi et al. aimed to estimate the prevalence and mechanism of ACL injury among Makkah City, Saudi Arabia. They found that the most common cause of ACL injury was sports ( $\mathrm{n}=181)$. ACL injuries occurred owing to rapid acceleration $(n=18)$ or deceleration $(n=20)$ as well as traffic accidents $(n=16)$ and work-related causes $(n=14)$ [9].

Another study conducted by Alghamdi et al. found that the prevalence of cruciate ligament injuries among physical education students of Umm Al-Qura University was 5.3\%; most injuries involved the ACLs (60\%), while $10 \%$ involved the posterior cruciate ligaments; the injured ligament was unknown in the remaining $30 \%$. The right knee was involved in $70 \%$ of injuries, while $30 \%$ were left knee injuries [10]. 
Injuries to the ACL of the knee are immediately disabling, rehabilitation takes a substantial period of time, and other associated articular injuries are often related to it, as a result, the risk of early-onset posttraumatic osteoarthritis is increased irrespective of the treatment applied [11]. Rotational stability of the knee can be restored by ACL repair; however, it remains unclear whether it prevents knee joint degeneration [12].

Numerous risk factors are associated with an increased risk of ACL injury, such as female sex, bony geometry of the knee, familial predisposition, and prior repair of the ACL [13].

Only a few studies have investigated the association between ACL injury and other associated injuries in the Saudi Arabian population, specifically the western region.

In this study, we addressed the prevalence of ACL injuries and their association with different types of knee injuries among attendees of King Abdulaziz University Hospital (KAUH), Jeddah, Saudi Arabia.

\section{Materials And Methods \\ Study setting}

This study was conducted between September 2010 and September 2018 at KAUH, a tertiary center that is the largest educational hospital on the west coast of Saudi Arabia.

\section{Study design and population}

This was a retrospective record review that included all patients between 18 and 40 years old who had a confirmed ACL injury after magnetic resonance imaging (MRI) of the knee between September 2010 and September 2018 at KAUH. All imaging was performed within seven days of the index ACL injury. However, patients with previous knee injuries, congenital abnormalities, or degenerative diseases were excluded. This study was approved by the institutional review board of KAU (Reference No. 359-18). The need for informed consent was waived owing to the retrospective nature of the study.

A total of 136 patients matched our criteria and were included in our study. All patients underwent imaging using a 1.5-T Symphony system (Siemens Medical Solutions, Erlangen, Germany), 3-T Verio system (Siemens Medical Solutions, Erlangen, Germany), or 3-T Skyra system (Siemens Medical Solutions, Erlangen, Germany). All examinations included at least one of the following sequences: axial, coronal, or sagittal images were obtained using conventional, fast spin-echo, turbo spin-echo, proton densityweighted, or T2-weighted sequences. Additional sequences included T1-and T2-weighted gradient-recalled echo sequences. All fast and turbo spin-echo sequences were fat-suppressed.

\section{Data entry and statistical analysis}

We used Google Forms, 2016 edition, to develop a data sheet consisting of two sections including the following: demographics (age, sex, and nationality) and MRI findings (type and side of ACL injury, any associated injuries, its relation to meniscus, bone injury, and collateral ligaments). After collecting the data, SPSS version 21 (IBM Corp., Armonk, NY, USA) was used for data entry and data analysis. Categorical variables including primary variables are described using frequencies. Continuous variables for normally distributed are described using mean and standard deviation (SD). Bivariate analysis was conducted for categorical variables using the chi-square test to check for all possible relations of ACL injury. A test with a $\mathrm{P}$-value $<0.05$ was considered statistically significant.

\section{Results}

The age of all included patients with ACL injury ranged from 18 to 40 years, with a mean age of $28.89 \pm 5.38$ years (Figure 1).

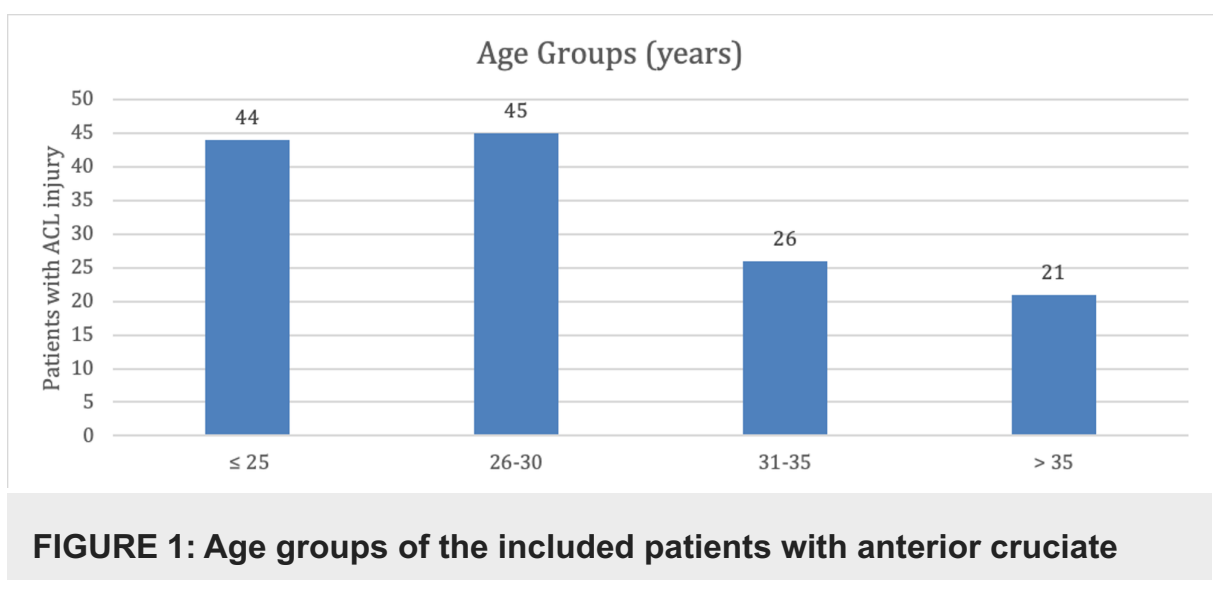




\section{Cureus}

\section{ligament $(A C L)$ injury}

The ACL injury was located on the right side in approximately two-thirds of patients (62.5\%). In the majority of patients $n=100(73.5 \%)$, the ACL tear was complete, and in the remaining ( $n=36,26.5 \%)$, it was partial or spiral (Figure 2).

Type of ACL tear

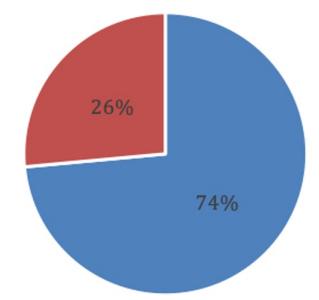

- Complete $\quad$ Others (partial and spiral)

FIGURE 2: Type of anterior cruciate ligament (ACL) tear in the included patients with ACL injury

Associated injuries were found in the majority of patients (73.5\%) (Figure 3).

\section{Associated injuries}

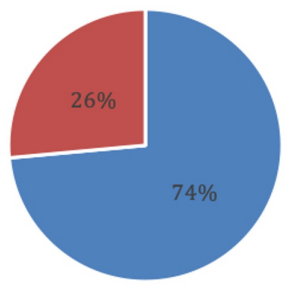

- Associated injuries - No associated injuries

FIGURE 3: Associated injuries in the included patients with anterior cruciate ligament $(A C L)$ injury

The medial meniscus was injured in 67 patients (49.3\%), whereas the lateral meniscus was injured in 22 patients (16.2\%). Regarding collateral ligament injuries, the medial collateral ligament was injured in six patients (4.4\%), the lateral collateral ligament in four patients (2.6\%), and both collateral ligaments in three patients (2.2\%). Bone injuries in the included patients with ACL injury were bone edema (FLC, tibia, fibula or femur) in 32 patients (23.5\%) and Segond fracture in nine patients (6.6\%). The two women included were aged $\leqslant 25$ years. There was a significant relationship between the age group and side of ACL injury $(\mathrm{P}<0.05)$ but not between the age group and presence of associated injury, type of ACL tear, meniscus injury, bone injury, or type of collateral ligament injury in all patients $(\mathrm{P}>0.05)$. Most patients were men $(\mathrm{n}=134,98.5 \%)$ (Table 1).

\begin{tabular}{|c|c|c|c|c|c|c|c|}
\hline & & \multicolumn{4}{|c|}{ Age group (years) } & \multirow{2}{*}{ Total $(\mathrm{N}=136)$} & \\
\hline & & $\leq 25(\mathrm{~N}=44)$ & $26-30(\mathrm{~N}=45)$ & $31-35(\mathrm{~N}=26)$ & $>35(\mathrm{~N}=21)$ & & \\
\hline \multirow{4}{*}{ Sex } & & 2 & 0 & 0 & 0 & 2 & \multirow{4}{*}{0.236} \\
\hline & & $4.5 \%$ & $0 \%$ & $0 \%$ & $0 \%$ & $1.5 \%$ & \\
\hline & \multirow{2}{*}{ Male } & 42 & 45 & 26 & 21 & 134 & \\
\hline & & $95.5 \%$ & $100.0 \%$ & $100.0 \%$ & $100.0 \%$ & $98.5 \%$ & \\
\hline
\end{tabular}




\section{Cureus}

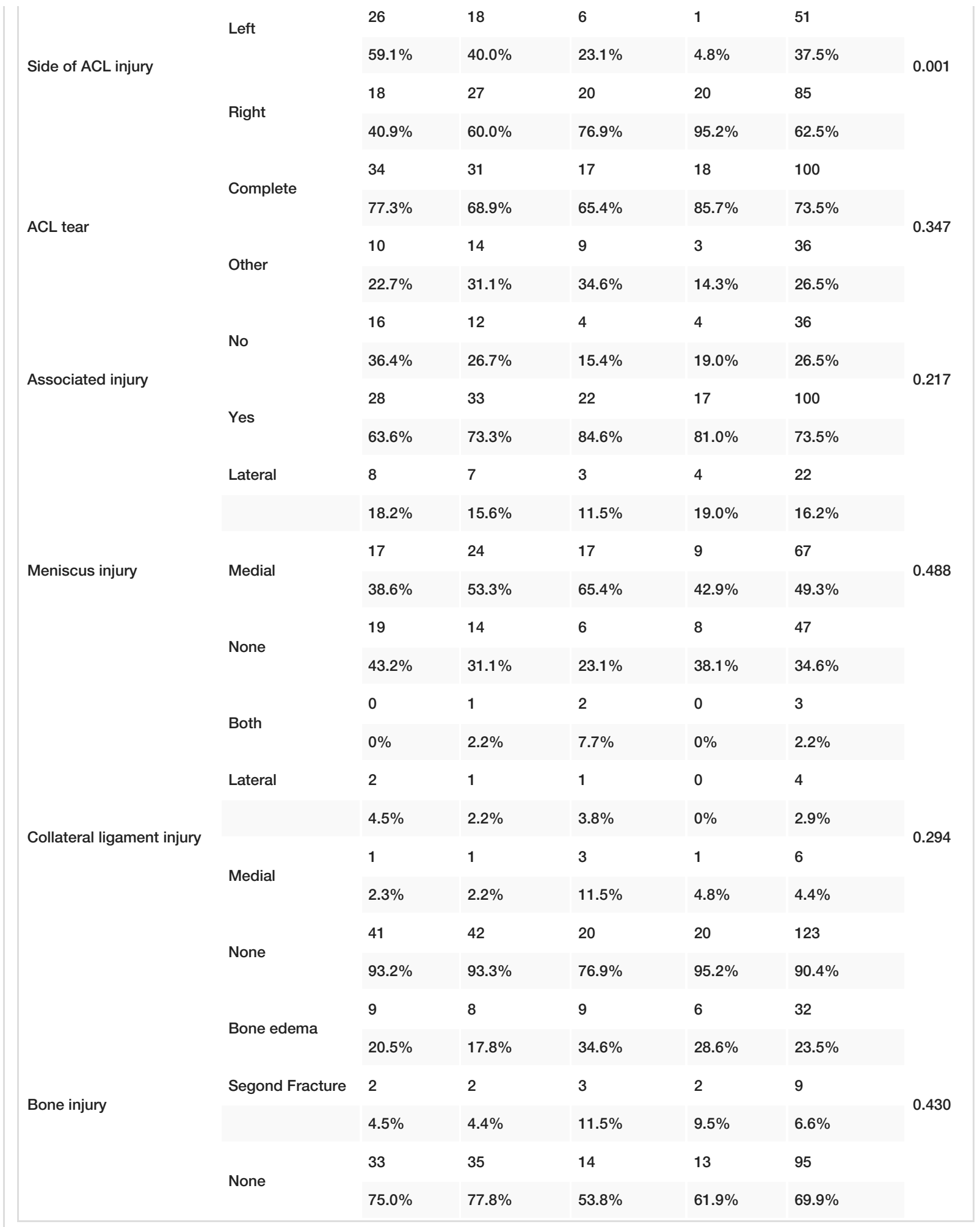

TABLE 1: Relationship between the age group and side of anterior cruciate ligament (ACL) injury, associated injury, type of $A C L$ tear, meniscus, bone injury, and collateral ligament in the included patients with $A C L$ injury

There was also a significant relationship between the type of ACL tear and side of ACL injury and presence of associated injury $(\mathrm{P}<0.05)$ but not between the type of ACL tear and age, sex, meniscus injury, bone injury, or type of collateral ligament injury in all patients $(\mathrm{P}>0.05)$ (Table 2). 


\section{Cureus}

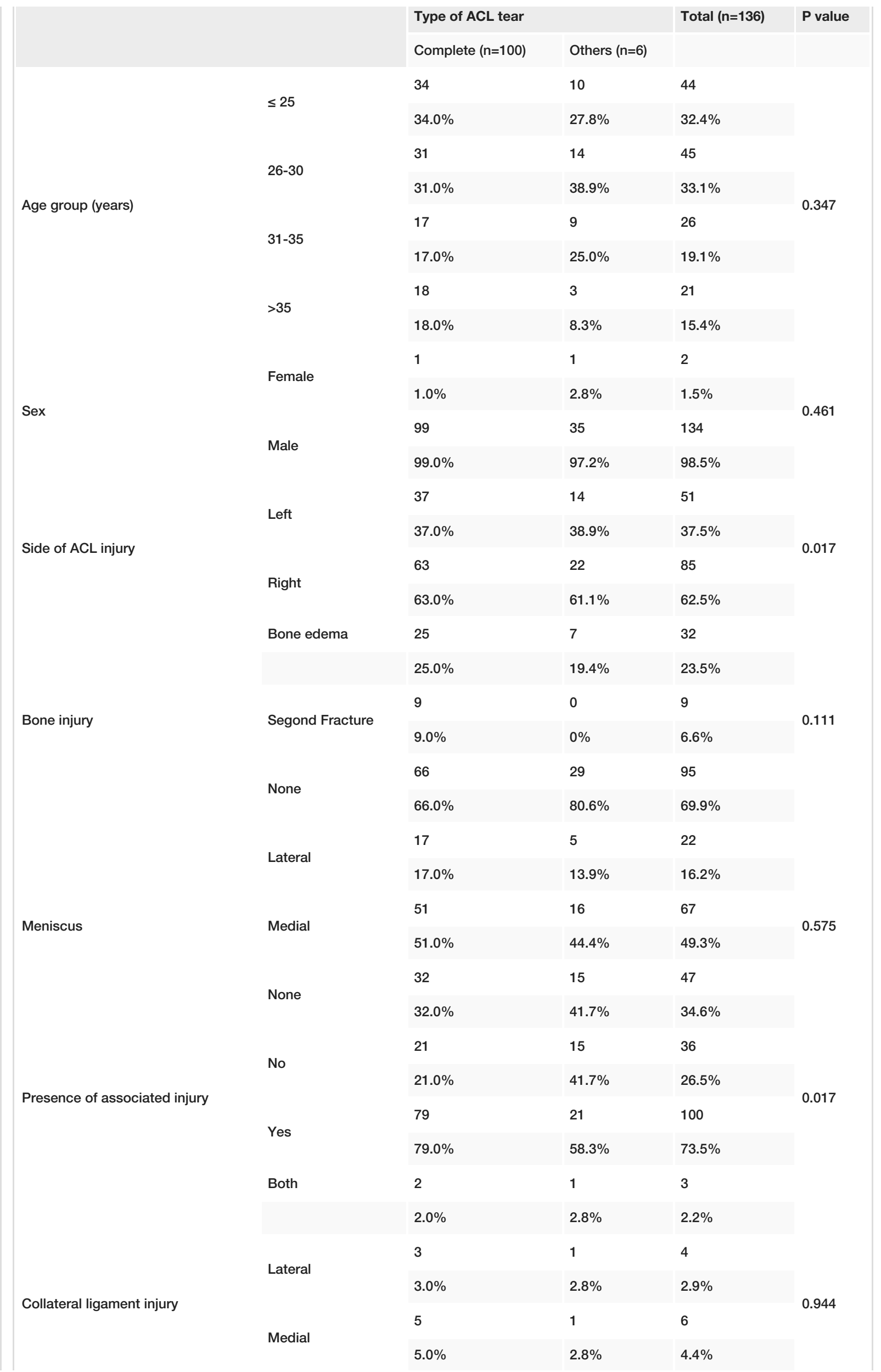




\section{Cureus}

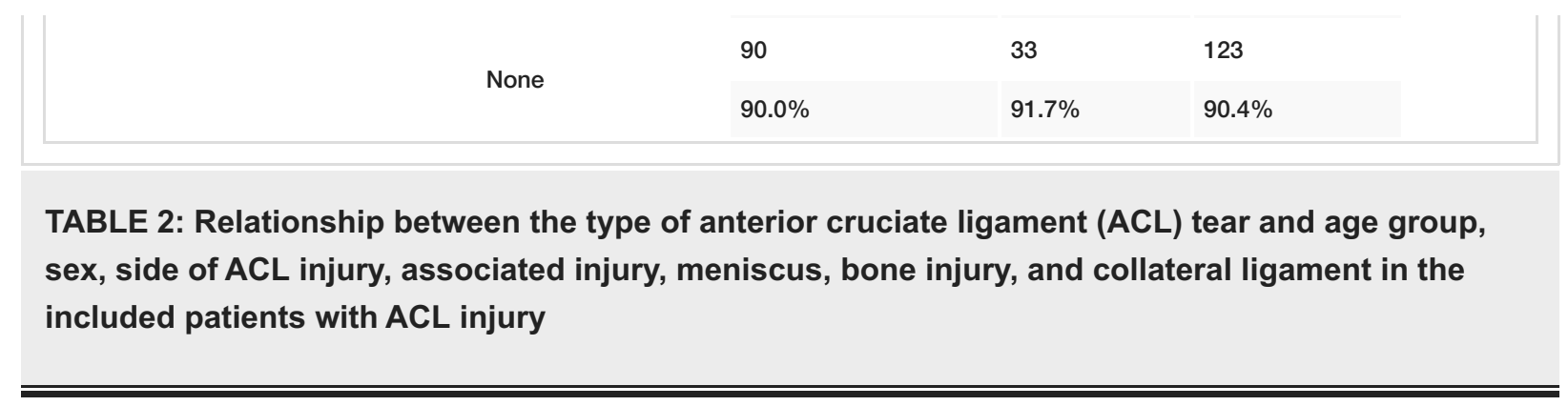

\section{Discussion}

The study aimed to address the prevalence of ACL injuries and its association with different types of knee injuries in these patients. The majority of ACL injuries were on the right side (62.5\%), whereas left-sided injures were less common (37.5\%).

Similar to our results, in Arar City, Kingdom of Saudi Arabia, another cross-sectional study was conducted among a representative sample of Northern Border University students; right-sided injuries were reported in $60.6 \%$ and left-sided injuries in $39.4 \%$ of cases [14]. A retrospective cross-sectional study conducted among students of physical education at Umm Al-Qura University found that right-sided injures accounted for $70 \%$ of cases, whereas left-sided injuries accounted for 30\% [10]. In addition, another study reported that rightsided injuries were the most common (56.9\%) [15].

Regarding the type of ACL tear, it was complete in $73.5 \%$ of cases and partial or spiral in $26.5 \%$ of cases in our study. In agreement with our results, another study reported that the ACL tear was complete in $54.9 \%$ of cases and partial in $38 \%$ of them [14]. In Makkah, another study reported partial ACL injury in $23.7 \%$ of cases and complete ACL injury in $37.9 \%$ of cases [9]. Moreover, another study found complete injury in $81.3 \%$ of cases and partial injury in $12.7 \%$ of cases [16].

Associated injuries were found in the majority of cases (73.5\%) in this study: bone edema (FLC, tibia, fibula, or femur) was reported in $23.5 \%$ of cases and Segond fracture in $6.6 \%$ of cases. In accordance with our findings, another study found that there was associated injury in $73.2 \%$ of cases [14]. Additionally, that study reported associated injuries of contusions of the knee in $50.7 \%$, twisting of the knee in $22.5 \%$, twisting of the foot in $11.3 \%$, wounds in the knee in $8.5 \%$, wounds and contusions on the body in $4.2 \%$, fractured hand in $1.4 \%$, and fractured femur in another $1.4 \%$ of cases [14]. The menisci play a crucial role in knee homeostasis, lubrication, joint stability, proprioception, and shock absorption [17]. ACL tears are frequently associated with meniscal injury. Numerous authors have described associations between the presence of a meniscal tear at the time of ACL reconstruction, time to surgery, and the number of instability episodes [18]. In our study, the medial meniscus was injured in $49.3 \%$ of cases, whereas the lateral meniscus was injured in $16.2 \%$. Similar to our results, another study found that $44.4 \%$ of cases had meniscal tears, of which $30.5 \%$ were medial, $7.2 \%$ were lateral, and $6.7 \%$ had both lateral and medial meniscal tears [19]. In contrast, Millett et al. study found that meniscal injury occurred more frequently in the medial meniscus than in the lateral meniscus [20]. Similarly, another study reported lateral meniscus represented $41 \%$ of cases, whereas medial meniscus represented $25.6 \%$ of them [21].

Ghodadra et al. studied the incidence of medial and lateral meniscal tears in 709 patients with ACL tears and found that $37 \%$ had medial meniscal tears and $41 \%$ had lateral meniscal tears, whereas $17 \%$ had both lateral and medial meniscal tears [22]. Hagino et al. showed that the incidence of meniscal tear was $72.7 \%$ (256 patients) in acutely injured knees, with medial meniscal tears only found in $11 \%$ of patients, lateral meniscal tears in $69 \%$, and both medial and lateral meniscal tears in $20 \%$ [23]. In this study, the incidence of medial and lateral meniscal tears was 49.3 and $16.2 \%$, respectively. The total percentage of both meniscal tears thus correlates with the findings obtained from previous studies. However, we found that the medial meniscus is more commonly injured than the lateral meniscus. This appears to be due to the strong attachment of the medial meniscus to the joint capsule and the deep fibers of the medial collateral ligament, making it more stable than the lateral meniscus, which does not connect with the lateral collateral ligament and has looser attachments with the joint capsule.

Regarding collateral ligament injuries, medial injury was reported in $4.4 \%$, lateral injury in $2.9 \%$, and bilateral injury in $2.2 \%$ of the cases in our study. In contrast to our results, another study reported that $4.5 \%$ of cases had collateral ligament injuries: the majority of them (2.4\%) had injuries to both collateral ligaments, $1.4 \%$ had a medial collateral ligament injury, and $0.6 \%$ had a lateral collateral ligament injury only [24].

Our study found a significant relationship between the age group and side of ACL injury $(\mathrm{P}<0.05)$ but not between the age group and presence of associated injury, type of ACL tear, meniscus injury, bone injury, and type of collateral ligament injury in all patients with ACL injury $(\mathrm{P}>0.05)$. 
There was a significant relationship between the type of ACL tear, side of ACL injury, and presence of associated injury $(\mathrm{P}<0.05)$ but not between the type of ACL tear and age, sex, meniscus injury, bone injury, or the type of collateral ligament injury in our patients $(\mathrm{P}>0.05)$. Regarding the relationship between bone injury and other injuries (meniscus and collateral ligaments), our study found a significant association with collateral ligament injury but not with meniscus injury.

Our study was limited by the small sample size and the fact that it was a single-center study. Although it would have been preferable to include all hospitals in Jeddah, our study investigated all injuries associated with ACL injury, which is very important.

\section{Conclusions}

This study investigated the association between ACL and other associated knee injuries using MRI for diagnosis. After assessing many different factors, we found no significant relationship between ACL injuries and meniscal, collateral ligament, or bone injuries. We recommend further research in this particular field with a larger and more divergent sample size. Multi-center studies are needed in the future to further support the results of the present study.

\section{Additional Information \\ Disclosures}

Human subjects: Consent was obtained by all participants in this study. Unit of Biomedical Ethics at King Abdulaziz University issued approval 359-18. The Research Ethical Committee (REC) recommended granting permission of approval to conduct the project. Animal subjects: All authors have confirmed that this study did not involve animal subjects or tissue. Conflicts of interest: In compliance with the ICMJE uniform disclosure form, all authors declare the following: Payment/services info: All authors have declared that no financial support was received from any organization for the submitted work. Financial relationships: All authors have declared that they have no financial relationships at present or within the previous three years with any organizations that might have an interest in the submitted work. Other relationships: All authors have declared that there are no other relationships or activities that could appear to have influenced the submitted work.

\section{Acknowledgements}

We would like to thank Editage (www.editage.com) for English language editing, and Abdulkarim Jawhari for his useful and helpful tips in this research project.

\section{References}

1. Lee S-M, Lee J-H: Effect of balance taping using kinesiology tape for a hamstring muscle injury and traumatic knee pain in an amateur university football player: a case report. Medicine. 2018, 97:e10973. 10.1097/MD.0000000000010973

2. Flandry F, Hommel G: Normal anatomy and biomechanics of the knee. Sports Med Arthrosc Rev. 2011, 19:82-92. 10.1097/JSA.0b013e318210c0aa

3. Vaienti E, Scita G, Ceccarelli F, Pogliacomi F: Understanding the human knee and its relationship to total knee replacement. Acta Biomed. 2017, 88:6-16. 10.23750/abm.v88i2-S.6507

4. Kilinc BE, Kara A, Celik H, Oc Y, Camur S: Is anterior cruciate ligament surgery technique important in rehabilitation and activity scores?. J Exerc Rehabil. 2016, 12:232-37. 10.12965/jer.1632614.307

5. Caplan N, Kader DF: Stiffness and laxity of the knee: the contributions of the supporting structures: a quantitative in vitro study. Classic Papers in Orthopaedics. Banaszkiewicz P, Kader D (ed): Springer, London; 2014. 137-39. 10.1007/978-1-4471-5451-8_33

6. Gianotti SM, Marshall SW, Hume PA, Bunt L: Incidence of anterior cruciate ligament injury and other knee ligament injuries: a national population-based study. J Sci Med Sport. 2009, 12:622-7. 10.1016/j.jsams.2008.07.005

7. Waldén M, Krosshaug T, Bjørneboe J, Andersen TE, Faul O, Hägglund M: Three distinct mechanisms predominate in non-contact anterior cruciate ligament injuries in male professional football players: a systematic video analysis of 39 cases. Br J Sports Med. 2015, 49:1452-60.

8. Dunn WR, Lyman S, Lincoln AE, Amoroso PJ, Wickiewicz T, Marx RG: The effect of anterior cruciate ligament reconstruction on the risk of knee reinjury. Am J Sports Med. 2004, 32:1906-14. $10.1177 / 0363546504265006$

9. Alrubayyi M, Alzahrani S, Alotaibi A, et al.: A survey of injuries to the anterior cruciate ligament among Makkah population, Saudi Arabia: prevalence and observations on injury mechanism. Int J Adv Res. 2018 6:814-9. 10.21474/IJAR01/7100

10. Alghamdi W, Alzahrani A, Alsuwaydi A, Alzahrani A, Albaqqar O, Fatani F: Prevalence of cruciate ligaments injury among physical education students of Umm Al-Qura university and the relation between the dominant body side and ligament injury side in non-contact injury type. Am J Med Sci. 2017, 7:14-9. 10.5923/j.ajmms.20170701.04

11. Lohmander L, Östenberg A, Englund M, Roos H: High prevalence of knee osteoarthritis, pain, and functional limitations in female soccer players twelve years after anterior cruciate ligament injury. Arthritis Rheum. 2004, 50:3145-52. 10.1002/art.20589

12. Neuman P, Englund M, Kostogiannis I, Friden T, Roos H, Dahlberg LE: Prevalence of tibiofemoral 
osteoarthritis 15 years after nonoperative treatment of anterior cruciate ligament injury: a prospective cohort study. Am J Sports Med. 2008, 36:1717-25. 10.1177\%2F0363546508316770

13. Smith HC, Vacek P, Johnson RJ, Slauterbeck JR, Hashemi J, Shultz S, Beynnon BD: Risk factors for anterior cruciate ligament injury: a review of the literature-part 1: neuromuscular and anatomic risk. Sports Health. 2012, 4:69-78. 10.1177\%2F1941738111428281

14. Alrwaili AA, Hussain MA, Abo El-fetoh NM: Cruciate ligament injury among students of Northern Border University, Saudi Arabia. Egypt J Hosp Med. 2018, 73:6789-96. 10.12816/ejhm.2018.16183

15. Bispo Júnior RZ, Kawano CT, Guedes AV: Chronic multiple knee ligament injuries: epidemiological analysis of more than one hundred cases. Clinics. 2008, 63:3-8. 10.1590/S1807-59322008000100002

16. Schilaty ND, Nagelli C, Bates NA, Sanders TL, Krych AJ, Stuart MJ, Hewett TE: Incidence of second anterior cruciate ligament tears and identification of associated risk factors from 2001 to 2010 using a geographic database. Orthop J Sports Med. 2017, 5: 10.1177\%2F2325967117724196

17. Lawrence JTR, Argawal N, Ganley TJ: Degeneration of the knee joint in skeletally immature patients with a diagnosis of an anterior cruciate ligament tear: is there harm in delay of treatment?. Am J Sports Med. 2011, 39:2582-7. 10.1177\%2F0363546511420818

18. Christino M, Willimon SC, Perkins C, Schaafsma B, Busch M: The rate of meniscus tears in association with anterior cruciate ligament injuries increases with age. Orthop J Sports Med. 2019, 7:10.1177\%2F2325967119S00171

19. Alassiri MM, Parameaswari PI, Algamdi YH, Mohtasib R, Sayed MG: Prevalence of menisci and anterior cruciate ligament tear among athletes in Saudi Arabia: a retrospective assessment with MRI. Asian J Res. 2019, 16-25. 10.26739/2433-202x

20. Kim H, Kim I, Song Y-W, et al.: The association between meniscal and cruciate ligament damage and knee pain in community residents. Osteoarthr Cartil. 2011, 19:1422-8. 10.1016/j.joca.2011.09.002

21. Millett PJ, Willis AA, Warren RF: Associated injuries in pediatric and adolescent anterior cruciate ligament tears: does a delay in treatment increase the risk of meniscal tear?. Arthroscopy. 2002, 18:955-9. 10.1053/jars.2002.36114

22. Ghodadra N, Mall NA, Karas V, et al.: Articular and meniscal pathology associated with primary anterior cruciate ligament reconstruction. J Knee Surg. 2013, 26:185-94. 10.1055/s-0032-1327450

23. Hagino T, Ochiai S, Senga S, Yamashita T, Wako M, Ando T, Haro H: Meniscal tears associated with anterior cruciate ligament injury. Arch Orthop Trauma Surg. 2015, 135:1701-6. 10.1007/s00402-015-2309-4

24. Samuel AM, Diaz-Collado PJ, Szolomayer LK, et al.: Incidence of and risk factors for knee collateral ligament injuries with proximal tibia fractures: a study of 32,441 patients. Orthopedics. 2018, 41:e268-e276. 10.3928/01477447-20180213-03 